\title{
Semantic Context Clues in Expository Texts for TOEFL iBT Reading Section Preparation
}

\author{
Yuliya N. Gorelova \\ PhD, Associate Professor, Kazan Federal University, Institute of Management, \\ Economics and FinanceKazan, Russian Federation \\ gorelovajuliya@gmail.com \\ Ekaterina O. Zalyaeva \\ PhD, Associate Professor, Kazan Federal University, Institute of Management, \\ Economics and Finance, Kazan, Russian Federation \\ erunaz@mail.ru

\section{Dilyana D. Sungatullina} \\ Assistant Professor, Kazan Federal University, Institute of Management, \\ Economics and Finance, Kazan, Russian Federation \\ dilyana87@mail.ru
}

\section{Doi:10.5901/mjss.2015.v6n1p551}

\section{Abstract}

TOEFL iBT (Test of English as a Foreign Language, Internet-Based Test) exam as an important component of the global educational environment attracts the attention of both linguists and educators. The problem of semantic context clues relating to TOEFL seems worth exploring as the results of the research can be applied by both test makers and test takers. Expository texts as the first type of texts explored constitute the material of the research, which was aimed at the revealing the types of semantic context clues employed in expository texts, their types and significance. The results of the research revealed 13 single semantic clues types and 15 patterns for double semantic clues. The primary importance is given to single direct context clues, followed by indirect description and restatement due to their structural clarity and explicit definition of the unknown word. Double context clues are employed where a single context clue is not enough to disclose the meaning of an unfamiliar vocabulary item, facilitating the process of unknown word clarification and performing the function of a supplementary informational resource. The aim of the current research is to find out the most common types of semantic clues applied in the text influencing the test-takers excerpt comprehension and educe possible ways where semantic clues can be used in determining sentence meaning. The methodology described will enable teachers to successful development in their TOEFL preparation training courses and aid potential test-takers to overcome language barrier when taking the exam.

Keywords: expository texts, context clues, TOEFL iBT Reading section, testing discourse, academic reading.

\section{Introduction}

Global educational environment, exchange and mobility programs as well as double diploma opportunities offered by many leading universities all over the world highlight the importance of ESL (English as a Second Language) proficiency. TOEFL iBT is the test of EAP (English for Academic Purposes) which is accepted by most of the higher educational establishments in various countries. It checks four basic language skills: reading, listening, speaking and writing. Reading comprehension section being one of the largest and complex, includes a variety of text types as well as various task designs. Success in passing the reading subtest depends widely on the vocabulary size.

Vocabulary, its breadth and depth in particular, is an important predictor of academic success (Syyed Muhammed Alavi, 2012:376), which is also proved by Enright et.al. in TOEFL 2000 Reading Framework (Enright, et.al.). Though it is impossible to be an expert in all professional fields covered by TOEFL iBT reading texts, i.e. to know all the specific terms, and it is not implied. One of the test objectives is to check the level of reading comprehension skills.

They include five types: (1) deducing the meanings of word from context, (2) understanding the forms and meanings of non-idiomatic phrases, (3) understanding sentence meaning through syntactical structures, (4) recognizing and understanding rhetorical structures, and (5) critical reading skills (John, 1999:1). 
The first one seems to be in the focus of our attention as the aim of the current research is to find out the most common types of semantic clues applied in the text influencing the test-takers excerpt comprehension and educe possible ways where semantic clues can be used in determining sentence meaning.

\section{Methods and Materials}

Material for the research is taken from "Cambridge Preparation for The TOEFL Test iBT" By Jolene Gear And Robert Gear Book and covers 7 expository texts as the first group of texts the researchers are exploring.

The authors utilized textual observations for identifying and classifying the texts, using their formal characteristics.

The prevailing research instrument is the semantic analysis performed by the authors, which was aimed at identifying key words and context clues for their interpretation. The key words were chosen with the assumption that potential test takers have at least B2 language proficiency according to the European framework.

The research paper uses qualitative methods for description and interpretation of the various context clues used in reading passages; quantitative methods for calculating the percentage of each context clue type in the texts as well as the clues typical for a certain text type. Descriptive statistics was applied for summarizing data to make them more comprehensible.

The methodology described will enable teachers to successful development in their TOEFL preparation training courses and aid potential test-takers to overcome language barrier when taking the exam.

\section{Theoretical Review}

\subsection{Reading comprehension within the framework of TOEFL}

Major theories on the nature of reading and the stages of its development formulated both in linguistics (Gough \& Tunmer, 1986; Hoover \& Gough, 1990; McKenna \& Stahl, 2009; Scarborough, 2001) and language teaching (Chall, 1983; Ehri, 2004; Spear-Swerling \& Sternberg, 1996) focus on the following distinct contributors which can be regarded as key factors in reading comprehension process: language comprehension, word recognition and strategic knowledge. In spite of considerable evidence that background and linguistic knowledge act as a guarantee of a test taker's success in TOEFL, there're still other variables which can affect the level of their performance and, thus, require careful consideration.

Reading itself encompasses four crucial elements: the text, the reader, the interaction between the reader and the text, the mental state of the reader after the text interaction (Guthrie \& Scafiddi, 2004:225). Reading comprehension deals with the consequences of that interaction, notably with the processes of constructing conceptual knowledge from a text. Each word and phrase in a written text makes a great contribution into the reader's job of making inferences and integrating propositions in order to create a coherent model of a given text.

The frames of TOEFL, designed to assess English proficiency in non-native speakers, transform the reader's incentives to deal with a text. Testing discourse determines the text organization (both physical presentation and text structure), subject scope, genre, the level of its difficulty as well as reader's microskills, macroskills and strategies for reading.

Brown distinguishes 4 types of reading: perceptive (presupposes the focus on certain words, letters and punctuation), selective (is used in true/false, multiple-choice, matching, picture-cued tasks, to check the reader's knowledge of lexical, grammatical or discourse features of language), interactive (is used to identify the reader's level of understanding explicit and implicit information of the text as well as conceptual meaning of a text) and extensive (is used for a global understanding of the text such as professional articles, essays, technical reports and books) (Brown, 2003:189). Since TOEFL is designed to simulate the types of reading tasks that students are expected to do in academic settings the reading section of this test is concentrated on the following main purposes:

1. Reading to find information;

2. Reading for basic comprehension;

3. Reading to learn;

4. Reading to integrate information across multiple texts (Enright \& Schedl, 2000:5).

Thus, we suggest that reading comprehension in TOEFL is a process of the reader's cognitive interaction and motivational involvement with the testing material (text) under the goal of obtaining quantitative and qualitative results of proficiency in the English language.

It is worth mentioning, that TOEFL iBT reading passages usually represent some excerpts from college-level text- 
books that would be used in introductions to a discipline or topic. The excerpts are changed as little as possible because the goal of the test is to assess how well test takers can read the kind of writing that is used in an academic environment. Thus, the passages, which are classified into three basic categories based on author purpose: (1) Exposition, (2) Argumentation, and (3) Historical, cover a variety of subjects.

As long as expository texts are the basic type of textual material which students deal with in the academic discourse, we consider their layout in more detail.

First, expository texts purvey a tone of authority, since the authors possess authentic and accurate information on the subjects they write about (Fisher \& Frey, 2008). Second, these texts follow a style that is distinctly different from that of narrative text. Expository text uses clear, focused language and moves from facts that are general to specific and abstract to concrete. Another aspect of expository texts is that they utilize specific structures to present and explain information (Burke, 2000). And, it has long been known that the ability to recognize text structure enhances the student's ability to comprehend and recall the information read (Armbruster, Anderson, \& Ostertag, 1989).

As we have mentioned before, TOEFL texts vary in the subject scope and the type of their organization, thus becoming an additional challenge for a test taker. In this case, the logical connections among ideas in the text and their relations to each other play a dominant role in the test taker's understanding the gist of the text. Sidenberg suggests that a good topic organization, placement of a topic sentence at the beginning of a paragraph, the usage of recognizable patterns in superordinate/subordinate relationships (Sidenberg, 1986:7) and textual clues to the relevant information of the text (both semantic and syntactic) contribute to a reading comprehension process. Taking into consideration that TOEFL focuses on the meaning of a word or phrase within the context of the passage we will concentrate our attention on the role of context clues as a means of reading comprehension process facilitation.

\subsection{Context clues classification scheme}

Testing discourse involves the patterns of direct and indirect communication between an examiner and a test taker fixed in written and oral texts. Being a complex and socially determined phenomenon, testing discourse serves as an instrument for test taker's academic achievements control and assessment at a certain period of educational process. TOEFL as a form of English proficiency control in non-native speakers excludes all the options for dictionary or any other consultations in the exam process and especially in the reading section of the exam. This fact requires that a test taker employs context clues to figure out the meaning of unfamiliar words in a reading text, to comprehend its factual information as well as to make inferences to get the gist of the text.

Nation and Coady (1988) define context as morphological, syntactic, and discourse information in a given text which can be classified and described in terms of general features. Eanes (1996:338) and Spears (2000:98) claim that context clues denote a special usage of a word or word expressions in a certain sentence or extract with the aim of revealing the meaning of another word, the notion of which a reader is absolutely unaware of.

Written texts in TOEFL which serve as a means of testing material are selected, adopted in accordance with the discourse aims. Thus, structural and semantic patterns of texts for reading purposes in TOEFL, being a challenge for a test taker, purposely provide helpful context which will be of a great aid in a test taker's interaction with a new troublesome word. Thereby, a test taker's ability to use the context clues within the framework of TOEFL serves as an indicator of his proficiency and a high level of English usage.

Huckin and Bloch (1993:161) investigated various types of context clues facilitating reading comprehension process and determined the following basic ones: local linguistic constituents (syntactic and semantic collocations), global text representations (text schemas) and world knowledge. The results of their research showed that the most effective and frequently used clue was local linguistic constituent. Haynes (1993) shared this viewpoint outlining the fact that local co-text clues demonstrate a higher level of assistance to readers in a reading comprehension process in comparison with global ones.

Kusumarasdyati (2001) distinguishes four types of context clues that can be implemented in the process of reading comprehension: semantic, syntactic, picture and internal clues. The internal clues imply the knowledge of morphemes (the smallest unit of meaning) such as prefixes, suffixes, combining forms, and word roots, as well as their meanings. Picture clues are graphic illustrations of a textual content which can be used in a word cognition process. Syntactic clues presuppose the reader's knowledge of sentence structure and functional distinctions of words within a sentence. This type of clues is linguistic in nature and usually explored in collaboration with semantic clues, a detailed investigation of which will be presented further.

Semantic clues are derivatives of the words, phrases and sentences which an unknown word is enclosed into (Burns \& Roe, 1984:103). Harris \& Sipay (1980) underline that semantic clues effectiveness is the subject to the following 
conditions: the reader's background knowledge and the knowledge of words surrounding the new one.

Much has been done in the field of context clues classification (Ames, 1966; Dulin, 1970; Robinson, 1976; Seibert, 1945; Spears, 2000). Robinson (1976:62) distinguished 8 types of semantic clues: statement of meaning, definition by example, definition by synonym, definition by experience, definition by description, definition by comparison, definition by contrast and reflection of mood, tone or setting. In spite of a rich diversity of semantic clues types presented in Robinson's classification, it lacks distinct features which can help a reader to identify a semantic clues type in an accurate way. On the contrary, Spears's explanation doesn't outline the variety of options which can serve as semantic clues in a reading process.

In the following study we will stick to Ames's (1966:66) and Dulin's (1970:440-445) semantic clues classifications and will use them as a basis for TOEFL texts for reading purposes investigation. The obtained results of a thorough semantic clues classifications analysis are presented in the table below:

Table 1: Context clues classification

\begin{tabular}{|c|c|c|c|}
\hline № Clue type & Explanation & Example & Signs \\
\hline $\begin{array}{l}\text { Language } \\
\text { Experience or } \\
\text { Familiar } \\
\text { Expressions }\end{array}$ & $\begin{array}{l}\text { The meaning of the unknown word which acts as a } \\
\text { part of a phrase or idiomatic expression can be } \\
\text { determined through the reader's knowledge of familiar } \\
\text { expression. }\end{array}$ & $\begin{array}{l}\text { Scientists have actually detected tiny crystals of } \\
\text { magnetite in the OLFACTORY' tract of some } \\
\text { species. }\end{array}$ & $\begin{array}{l}\text { Familiar idiomatic } \\
\text { expression }\end{array}$ \\
\hline 2 Indirect Description & $\begin{array}{l}\text { A reader can apply to the phrase that defines the } \\
\text { unknown word or the phrase which contains the } \\
\text { unknown word. }\end{array}$ & $\begin{array}{l}\text { She (the goddess Ishtra) holds a SCIMITAR in } \\
\text { her left hand ... }\end{array}$ & Not distinguished \\
\hline 3 Direct Description & $\begin{array}{l}\text { The use of definite and descriptive passages to } \\
\text { describe the real meaning of the unknown word or the } \\
\text { phrase. }\end{array}$ & $\begin{array}{l}\frac{\text { The net movement of water is roughly at } 90}{\text { degrees from the wind direction and is known }} \\
\text { as EKMAN TRANSPORT. }\end{array}$ & $\begin{array}{l}\text { Mean(s), is, that is, thus, } \\
\text { is (are) used, in } \\
\text { summary }\end{array}$ \\
\hline 4 Words in Series & $\begin{array}{l}\text { The meaning of the unknown word can be deduced } \\
\text { through the series of words, phrases or ideas, which } \\
\text { this word belong to. A reader recognizes this series or } \\
\text { group organizations and then uses them as an aid. }\end{array}$ & $\begin{array}{l}\text { These artifacts are usually around two to three } \\
\text { centimeters in length and generally made of } \\
\text { stone, although sometimes bone, glass, shells, } \\
\text { or IVORY was used. }\end{array}$ & and \\
\hline $\begin{array}{l}5 \text { Comparison / } \\
\text { Contrast }\end{array}$ & $\begin{array}{l}\text { The usage of antonyms or definitive words and } \\
\text { phrases, to convey the exact opposite or logical } \\
\text { antithesis of the unknown word. }\end{array}$ & $\begin{array}{l}\text { As the organism migrates, it leaves behind } \mathbf{A} \\
\text { TRACK OF SLIME rather like a garden slug. }\end{array}$ & $\begin{array}{l}\text { Rather than, unlike, but, } \\
\text { however, instead of, in } \\
\text { contrast, or, although }\end{array}$ \\
\hline 6 Synonym & $\begin{array}{l}\text { Pairing of the unknown word with synonyms or } \\
\text { synonymous phrases in series; linking the unknown } \\
\text { word with a synonymic phrase through punctuation } \\
\text { (commas or dashes) }\end{array}$ & $\begin{array}{l}\text { Agriculture is one important SPIN-OFF. Fresh- } \\
\text { water for drinking and irrigation is another by- } \\
\text { product. }\end{array}$ & $\begin{array}{l}\text { Too, also, similar } \\
\text { sentence structure, :- }\end{array}$ \\
\hline $\begin{array}{l}7 \text { Tone, Setting, } \\
\text { Mood }\end{array}$ & $\begin{array}{l}\text { One of the most difficult semantic clues. The choice of } \\
\text { particular words sets a certain mood or tone of the text } \\
\text { and its setting, which can help a reader to infer the } \\
\text { meaning of the unknown word }\end{array}$ & $\begin{array}{l}\text { The starchiness in his voice and the scowl on } \\
\text { this face warned us that } \\
\text { father was in a captious mood. Absolutely } \\
\text { nothing suited him! Dinner } \\
\text { was too late-the meat was too cold-the coffee } \\
\text { was too hot! }\end{array}$ & $\begin{array}{l}\text { General impression } \\
\text { conveyed by a sentence } \\
\text { or a group of sentences. }\end{array}$ \\
\hline 8 Reference & $\begin{array}{l}\text { The usage of referral signal words to identify the } \\
\text { meaning of the unknown word. }\end{array}$ & $\begin{array}{l}\text { Also at this time artisans used small rotating } \\
\text { DRILLS, and these allowed them to produce } \\
\text { circular and semicircular shapes ... }\end{array}$ & It, this, that, these \\
\hline 9 Restatement & $\begin{array}{l}\text { The meaning of the unknown word can be judged } \\
\text { through a defining phrase which can be separated } \\
\text { with the term "or", or with commas. }\end{array}$ & $\begin{array}{l}\text { Sometimes CUNEIFORM, a wedge-shaped } \\
\text { writing usually scratched into wet clay with } \\
\text { reeds, was included in the overall design. }\end{array}$ & Or, , ,.., \\
\hline 10 Preposition & $\begin{array}{l}\text { The usage of prepositions as clues to the meaning of } \\
\text { the unknown word which acts as an object of that } \\
\text { preposition }\end{array}$ & $\begin{array}{l}\text { However, since a complete ROTATION around } \\
\text { the Earth is shorter the further one is away from } \\
\text { the Equator ... }\end{array}$ & Preposition \\
\hline $\begin{array}{l}11 \text { Cause / Effect } \\
\text { Pattern }\end{array}$ & $\begin{array}{l}\text { Setting up a Cause-Effect relationship from which the } \\
\text { meaning of the new word can be logically inferred }\end{array}$ & $\begin{array}{l}\text { Various elements including rubidium are } \\
\text { INCORPORATED into minerals as they } \\
\text { crystallize from magma or metamorphic rock. }\end{array}$ & $\begin{array}{l}\text { Because, since, as, } \\
\text { because of, therefore, } \\
\text { thus }\end{array}$ \\
\hline 12 Modification & $\begin{array}{l}\text { The meaning of the unknown word is explained } \\
\text { through a relative clause which follows it. Relative } \\
\text { pronoun acts as a signal for a clue }\end{array}$ & $\begin{array}{l}\text { lodine is a well-known example of a TRACE } \\
\text { MINERAL whose lack in the body creates an } \\
\text { easily treated disease. }\end{array}$ & $\begin{array}{l}\text { Which, who, where, that, } \\
\text { whose }\end{array}$ \\
\hline 13 Example & $\begin{array}{l}\text { Example is used as a key to clarify the word's hidden } \\
\text { meaning }\end{array}$ & $\begin{array}{l}\text { In a closed cycle system the warm surface } \\
\text { water is used to boil a fluid such as AMMONIA. }\end{array}$ & For example, such as \\
\hline
\end{tabular}

${ }^{1}$ The bold words in capital letters represent difficult words to be guessed; italicized words are signs and underlined words are contextual clues that may facilitate the process of guessing. 


\section{Results}

To illustrate how the meaning of the unknown word can be revealed through semantic context clues we investigated 7 expository texts taken from the reading section of "Cambridge Preparation for the TOEFL Test (4th ed.)" by Jolene Gear and Robert Gear. We elicited 104 semantic context clues, and classified them into Single semantic clues, i.e. clues applied not more than once within a sentence, and Double semantic clues, i.e. where the meaning of the unknown word is disclosed with the help of different context clues simultaneously. The pie chart presented below accurately depicts frequency of semantic clues usage: Single semantic context clues happened to outnumber Double clues significantly ( $72 \%$ and $28 \%$ respectively).

Chart 1: Single and Double Semantic Context Clues in expository texts types in TOEFL Reading Section

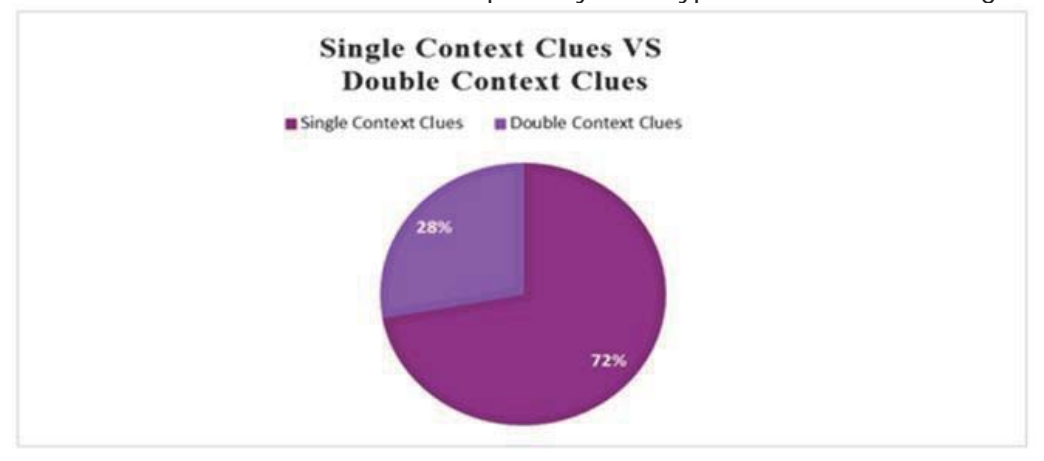

The high frequency of Single semantic context clues usage within a Reading section in TOEFL supports the view that the notion of most words, which are absolutely new for a test taker, is comprehensible, provided that a test taker possesses context clues detecting skills and in this way demonstrates his/her academic reading ability. Based on our set of data we can reasonably claim, that Double semantic context clues are implemented in a testing material in cases when the meaning of the unknown word cannot be revealed the first time it is analyzed, thus they can perform the function of supplementary informational resource.

In our current study we have also explored that double semantic context clues appear to form some patterns of joint usage. Bar-chart 1 presented below contains the results of double semantic context clues patterns investigation. Apparently direct and indirect description semantic clue types are the basic constituents in almost $66 \%$ of patterns examined. A thorough analysis of the sentences containing indirect and direct description clue types acting as components of double semantic clues exposes that they bring out more information about the unknown word than another constituent element does (consider the following example):

E.g.: Among other things, it creates the zones of upwelling by forcing surface waters apart (indirect description) and other (compare / contrast) zones of downwelling by forcing surface water together (indirect description).

Notwithstanding the fact that the notion of capitalized words can be partially guessed through the opposition, the key message is conveyed by the indirect description semantic clue type.

Chart 2. Double Semantic Context Clues Patterns in expository texts types in TOEFL Reading Section

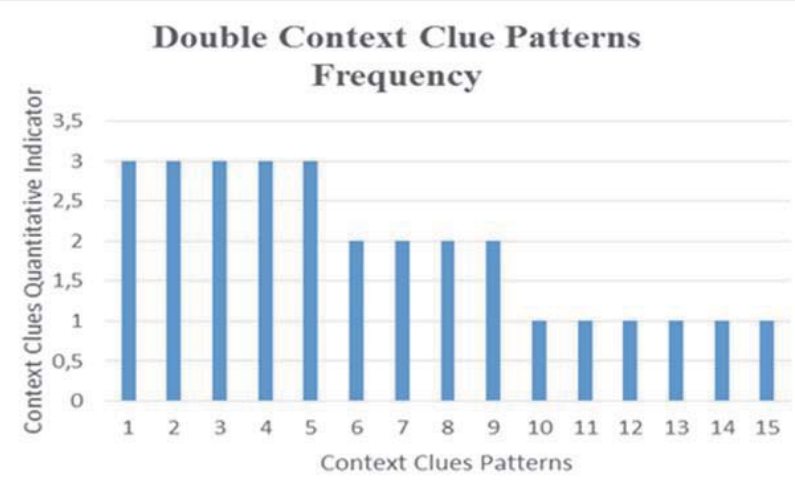


Direct description + Reference

1. Indirect description + Language experience or familiar expression

2. Indirect description + Preposition

3. Indirect description + Reference

4. Compare/Contrast + Language experience or familiar expression

5. Language experience or familiar expression + Cause / Effect pattern

6. Words in Series + Example

7. Words in Series + Preposition

8. Direct description + restatement

9. Indirect description + modification

10. Indirect description + Compare / Contrast

11. Language experience + example

12. Direct description + modification

13. Indirect description + cause / effect

14. Indirect description + example

The following step of the current research was dividing the semantic clues presented in the graph in accordance with the role they play in the sentence to help test takers in the unfamiliar word meaning guessing process. Let us illustrate the results obtained in the following bar chart:

Chart 3. Single Semantic Context Clue types frequency in expository texts types in TOEFL Reading Section

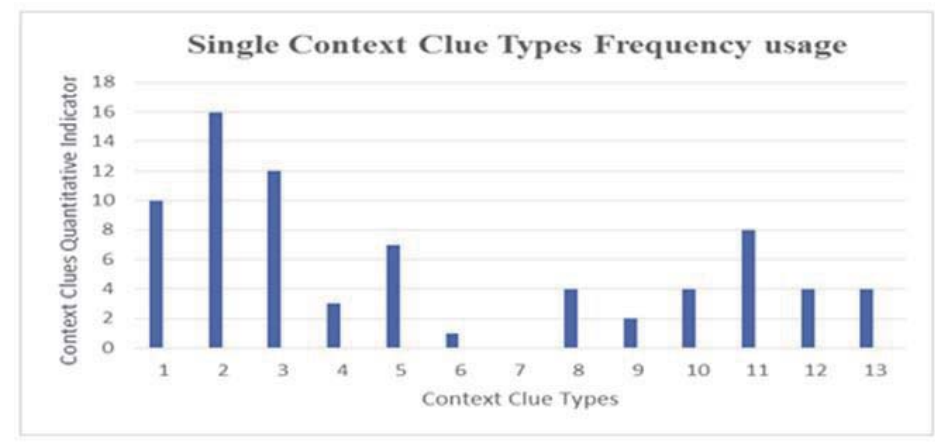

1. Language experience or familiar expression

2. Direct description

3. Indirect description

4. Word series

5. Contrast/Comparison

6. Synonym

7. Tone, setting, mode

8. Reference

9. Preposition

10. Cause / effect

11. Restatement

12. Example

13. Modification

The findings display that the nature of direct context clue type expressed in the explicit definitions and explanations of the unknown word, its structural clarity (prepositional phrases and dependent clauses, linking expressions) significantly facilitated comprehension process. Indirect description and restatement context clue types share the importance and frequency of implementation in TOEFL reading texts. These context clues are of a great importance and great value since they implicitly lead a test-taker to the understanding of a new word. It should be noted that such a density of language experience semantic clue type indicates the fact that TOEFL exam presupposes test taker's high-level of vocabulary knowledge and intensive reading activity.

The survey of other semantic context clue types in expository texts of TOEFL reading section illustrates their minor 
position in comparison with those, mentioned above.

\section{Discussions}

The main concern of this paper was the analysis of semantic context clues and the way they can be employed in the process of the unknown word investigation, which is illustrated below.

\subsection{Language Experience or Familiar Expression}

The nucleus of a radioactive atom disintegrates spontaneously and forms an atom of a different element while EMITTING radiation in the process.

Context: the process of a radioactive atom nucleus decay is attended by radiation.

The knowledge of the word radiation can help a test taker to understand that the process of beaming and rays sending is meant.

1) Direct Description

The front cells turn into a stalk, and the back cells climb up the stalk and form a spherical-shaped head known as SOROCARP.

Context: ts is a descriptive sentence, which explains the life cycle of a living organism.

The meaning of the unknown word is disclosed through a detailed explanation of the organism's external features "spherical-shaped head" and the usage of the phrase "known as".

2) Indirect Description

As the surface water in the ocean is moved by the wind, it tends to veer off at an angle of 45 degrees to the right or left.

Context: the movement of water surface is illustrated.

The meaning of the word "veer off" is implicitly stated in the manner of that movement.

3) Words in Series

At the first stage they (slime modes) are free-living, separate amoebae, usually inhabiting the forest floor and ingesting bacteria found in rotting wood, DUNG or dump soil.

Context: the sentence explains slime modes living environment and typical feeding.

The word "dung" comes together with the notion denoted by the words "rotting wood and dump soil", therefore a test taker may conclude that they are close in meaning.

4) Contrast / Comparison

When food or water is digested, the iodine it contains is either taken up by the thyroid or ELIMINATED from the body through the kidneys into the urine.

Context: the process of iodine absorption and destruction from the human body.

The usage of conjunction "either ... or" assists a test taker to comprehend that the word "taken up" is opposed to "eliminated", thus they are contrary in meaning.

5) Synonym

Agriculture is one important SPIN-OFF. Fresh-water for drinking and irrigation is another by-product. Context: agriculture and fresh-water are regarded as consequences of some activity.

Determiners "one - another", which are interrelated, act as key factors in understanding that "by-product" is a synonym of the unknown word as well as the similar structure of the consecutive sentences.

6) Reference

The main reason for this annual shifting of residence is that during the northern winters food become scarce and the cold temperature makes survival difficult. Some species are well adapted to these HARSH CONDITIONS, but for those that aren't, moving south to warmer conditions is advantageous.

Context: winter is considered as one of the factors for bird migration.

Pronoun "these" gives a full description of the unknown phrase.

7) Preposition

Now if an untethered object (or current) is moving northward away from the equator in the Northern Hemisphere, it will also maintain the initial speed imparted to it by the eastward rotation of the Earth.

Context: the speed of a moving object in relation to the Equator and Earth rotation is discussed.

The relationships between the unknown word followed by prepositions ("to", "by") and the rest parts of the sentence serve as a clue for guessing the meaning. 
8) Cause/Effect Pattern

There are also potential ecological drawbacks since the water DISCHARGES will change the water temperature and disturb some marine habitats.

Context: A harmful influence of some innovative technologies on marine habitats is analyzed.

Conjunction "since" indicates that there is a strong dependence between the words "drawbacks" and "discharges", thus a test taker recognizes that the unknown word conveys the meaning of negative consequences.

9) Restatement

All stars rotate around POLARIS, the pole star, and this movement seemed to give the birds the information they needed.

Context: the pole star coordinates the birds flying paths.

There's no explicit sign that indicated a contextual semantic clue, but commas which detach "the pole star" expression act as key element.

10) Example

In a closed cycle system the warm surface water is used to boil a fluid such as AMMONIA.

Context: the sentence depicts the usage of the surface water.

"Ammonia" is an example of "fluid".

11) Modification

The monarch (butterfly) at its larval stage feeds on the MILKWEED PLANT, which contains several substances that are toxic or unpalatable to vertebrate animals.

Context: the sentence presents the information about feeding habits of an insect.

The explanation of the word "milkweed plant" is provided with the help of the relative clause that follows it.

Having examined all the sentence structures to identify possible semantic clues, we found out the existence of a so called Double Context Clue that means having two semantic clues within a sentence simultaneously.

12) Double context clues

Among other things, it creates the zones of upwelling by forcing surface waters apart (indirect description) and other zones of downwelling by forcing surface water together (compare / contrast).

Context: a phenomenon of ocean waters motion is illustrated.

The notion of words is conveyed through the implicit motion's characterization and direct opposition.

\section{Conclusion}

This paper is based on expository texts analysis in TOEFL test in terms of Context semantic clues in reading comprehension as they help test takers to find out the logical connections among ideas in the text, which play a dominant role in their understanding the gist of the text. The results of current research show that TOEFL Reading section is replete with such context clues as Language Experience or Familiar Expression, Direct and Indirect Descriptions, Words in Series, Contrast / Comparison, Synonym, Reference, Preposition, Cause/Effect Pattern, Restatement, Example, Modification and double context clues. The latters are of greater interest for us as they present a number of certain clue patterns which in their turn facilitate the difficult word guessing process if the meaning of the unknown word wasn't revealed the first time it was analyzed. Along with this, the research shows that the high frequency of Single semantic context clues usage within a Reading section in TOEFL supports the view that the notion of most words, which are absolutely new for a test taker, is comprehensible, provided that a test taker possesses context clues detecting skills and in this way demonstrates his/her academic reading ability.

In this paper by Semantic clues we understand derivatives of the words, phrases and sentences which an unknown word is enclosed into (Burns, 1984:103). This fact requires that a test taker employs context clues to figure out the meaning of unfamiliar words in a reading text, to comprehend its factual information as well as to make inferences to get the gist of the text.

Thus, structural and semantic patterns of texts for reading purposes in TOEFL, being a challenge for a test taker, purposely provide helpful context which will be of a great aid in a test taker's interaction with a new troublesome word. Thereby, a test taker's ability to use the context clues within the framework of TOEFL serves as an indicator of his proficiency and a high level of English usage. 


\section{References}

Alavi, S. M., and Akbarian, I. (2012). The role of vocabulary size in predicting performance on TOEFL reading item types, in System, 40, (3): pp. 376-385.

Ames, W.S. (1966) The development of a classification scheme of contextual aids. Reading Research Quarterly 2, (1): pp. 57-82.

Armbruster, B. B., Anderson, T. H., \& Ostertag, J. (1989). Teaching text structure to improve reading and writing. Reading Research Quarterly, 22, 331-346.

Brown, H. Douglas (2004). Language Assessment: Principles and Classroom Instructions, New York: Longman.

Burke, J. (2000). Reading Reminders: Tools, Tips, and Techniques. Portsmouth, NH: Boynton/Cook.

Burns, P. and Roe, B. (1984). Teaching Reading in Today's Elementary Schools. Boston: Houghton Mifflin Company.

Dulin, K.L. (1970) Using context clues in word recognition and comprehension. Reading Teacher 23, (5): pp. 440-445.

Eanes, R. (1996). Content Area Literacy. New York: Delmar Publishers.

Enright M. K., Grabe W.et al. (2000). TOEFL 2000 Reading Framework: A Working Paper. Educational Testing Service. Princeton, New Jersey

Enright, M.K. and Schedl, M. (2000): Reading for a reason: Using reader purpose to guide test design (A Draft TOEFL 2000 Report). Princeton, NJ: Educational Testing Service.

Fisher, D., Frey, N., \& Lapp, D. (2008). Shared readings: Modeling comprehension, vocabulary, text structures, and text features for older readers. The Reading Teacher, 61, pp. 548-557.

Gear, J. \& Gear R. (2006) Cambridge Preparation for the TOEFL® Test Book with CD-ROM $4^{\text {th }}$ edition

Guthrie, J. T., \& Scafiddi, N. T. (2004). Reading comprehension for information text: Theoretical meanings, developmental patterns, and benchmarks for instruction. In J. T. Guthrie, A. Wigfield, \& K. C. Perencevich (Eds.), Motivating reading comprehension: Conceptoriented reading instruction. Mahwah, NJ: Lawrence Erlbaum Associates, Inc. pp. 225-248.

Harris, A.J. and Sipay, E.R. (1980). How to Increase Reading Ability. New York: Longman.

Haynes, M. (1993). Patterns and perils of guessing in second language reading. In T. Huckin, M. Haynes \& J. Coady (Eds), Second language reading and vocabulary learning. Norwood: Ablex. pp. 3-23.

Huckin, T. and Bloch, J. (1993). 'Strategies for inferring word-meanings in context: A cognitive model'. In T. Huckin, M. Haynes \& J. Coady (Eds), Second language reading and vocabulary learning. Norwood: Ablex. pp. 153-178.

Kusumarasdyati, A. A. (2001) Semantic and Syntactic Clues as Vocabulary Strategies in Reading Comprehension. [Online] Available: http://www.angelfire.com/journal/fsulimelight/context.html

Nation, P. and Coady, J. (1988). Vocabulary and Reading. In R. Carter et al. (eds.) Vocabulary and Language Teaching. London, UK: Longman. pp. 97-110.

Robinson, H. Alan, (1976). Teaching Reading and Study Strategies: The Content Areas. Boston: Allyn and Bacon, Inc.

Seidenberg, P.L.(1986).Getting the gist: Relating text processing research toreading and writing instruction for learning disabled secondary students (Document No...5). Long Island University Transition Project. $15 \mathrm{p}$.

Spears, D. M. (2000). Improving Reading Skill. New York: The Mc Graw-Hill Companies, Inc.

Weaver, C. A. and Kintsch, W. (1991). Expository text. In R. Barr, M. Kamil, P. Mossenthal, \& P. Pearson (Eds). Handbook of reading research 2, White Plains, NY: Longman. pp. 230-245. 